\title{
Cluster headache: what has changed since 1999?
}

\author{
Massimo Leone - Alberto Proietti Cecchini • \\ Vincenzo Tullo $\cdot$ Marcella Curone . \\ Paola Di Fiore · Gennaro Bussone
}

(C) Springer-Verlag Italia 2013

\begin{abstract}
The peripheral and central origin of pain in cluster headache $(\mathrm{CH})$ and trigeminal autonomic cephalgias (TACs) has been matter of debate. In the last decade, a number of information came from both animal and human studies. This paper briefly highlights main data from these studies. Taken together, there is now sufficient body of evidence indicating that $\mathrm{CH}$ and TACs can be regarded as a unique headache spectrum-syndrome, due to involvement of specific brain areas.
\end{abstract}

Keywords Cluster headache - Treatment .

Neurostimulation $\cdot$ Hypothalamus

Until 1988, cluster headache $(\mathrm{CH})$ was classified together with migraine under the section of "vascular headaches" [1]. For the first time in 1988 the International headache society (IHS) classification separated $\mathrm{CH}$ from migraine [2]. In the second IHS classification [2] $\mathrm{CH}$ was grouped together with other two primary headache forms: paroxysmal hemicrania $(\mathrm{PH})$, and short-lasting unilateral neuralgiform headache attacks with conjunctival injection and tearing (SUNCT) [3]. This group was named the trigeminal autonomic cephalalgias (TACs) and is characterised by

\footnotetext{
M. Leone - A. P. Cecchini - V. Tullo - M. Curone

P. Di Fiore · G. Bussone

Department of Neurology, Headache Centre and Pain

Neuromodulation Unit, C. Besta Neurological Institute and

Foundation, Milan, Italy

M. Leone $(\square) \cdot$ A. P. Cecchini

Department of Clinical Neuroscience, Headache Centre,

C. Besta Neurological Institute and Foundation,

Via Celoria 11, 20133 Milan, Italy

e-mail: leone.m@istituto-besta.it
}

attacks of unilateral head pain associated with ipsilateral craniofacial autonomic manifestations. Attack duration is the main feature that distinguishes the three TAC forms. The term TAC was first introduced by Goadsby and Lipton [4] in 1997 because of the simultaneous activation of trigeminal and parasympathetic craniofacial nerves both in these headache forms. The contemporary activation of these nerves could be due to pathological activation of the trigeminofacial brainstem reflex [4].

The peripheral and central origin of pain in TACs, mainly in $\mathrm{CH}$ has been matter of debate. Orbital phlebographies in $\mathrm{CH}$ and other headaches did not reveal differences and systemic signs of inflammation have never been reported in $\mathrm{CH}$ [5], thus excluding inflammation of the cavernous sinus as a source of the pain in $\mathrm{CH}$.

Vasodilation seems not to be the cause of pain in $\mathrm{CH}$ : intracranial vasodilation is not specific to $\mathrm{CH}$ as it is observed in experimental forehead pain [6]. In addition, $\mathrm{CH}$ can occur even if vasodilation is blocked by trigeminal nerve section [7].

Sumatriptan efficacy is due to the antagonistic effect on peripheral 5-HT1D (at trigeminal nerve endings) and 5-HT1B receptors (on the walls of intracranial blood vessels) [8]. Thanks to these effects on peripheral 5-HT1D and 5-HT1B receptors, sumatriptan could control $\mathrm{CH}$ pain by reducing the increased concentrations of calcitonin generelated peptide in the ipsilateral jugular vein during $\mathrm{CH}$ attacks [9].

A peripheral origin of pain in $\mathrm{CH}$ and TACs also comes from secondary forms of these headaches: under such circumstances the clinical characteristics of $\mathrm{CH}$ and TACs are rather often difficult to differentiate the primary forms [10]. In many cases, the lesions are located in the sella turcica or the sinus cavernosus [10], and surgical removal leads to resolution of the pain. 
Other observations indicate that activation of trigeminal nerve endings alone cannot explain the pain of $\mathrm{CH}$ (and other TACs). Other factors probably in the brain play a role in pain generation. Vasodilators such as alcohol, nitroglycerine [11], and the 5-HT2B agonist $m$-chlorophenylpiperazine [12], can precipitate $\mathrm{CH}$ attacks but only during the bouts. These observations point to a central permissive state allowing vasodilation being perceived as painful.

In a PET study, peripheral trigeminal activation occurs in $\mathrm{CH}$ [13] without provoking $\mathrm{CH}$ pain attacks; in addition, surgical lesioning of the trigeminal nerve does not always resolve the pain in $\mathrm{CH}$ as well as other TACs [14, 15]. It is of interest to note that sumatriptan retains its ability to stop $\mathrm{CH}$ attacks after complete trigeminal nerve section [7], indicating that its effect is not at peripheral level but in the brain. Other data also suggest that the trigeminal nerve is not crucial in $\mathrm{CH}$ and TACs pain. In a large study on $\mathrm{CH}$ patients, $48 \%$ reported the headache outside the trigeminal distribution [16]. In $\mathrm{PH}$ pain can occur in various nontrigeminal areas, occipital (42\%), neck (32\%), ear (13\%), ipsilateral shoulder (10\%), and arm (10\%) [17]. In SUNCT pain can occur in the back of the head and neck in $31 \%$ and in the ear in $6 \%$ [18].

The clockwork regularity of $\mathrm{CH}$ attacks and the seasonal recurrence of $\mathrm{CH}$ led to the hypothesis that a biological clock in the hypothalamus was involved in $\mathrm{CH}$ [11]. In the same direction go the observations that attacks can be provoked by napping [11], and the shift to their regular times after changing time zone [11]. Neuroendocrinological abnormalities have been documented in $\mathrm{CH}$ substantiating hypothalamic involvement in $\mathrm{CH}$ [19].

$\mathrm{CH}$ and TACs should be regarded as a syndrome, with a central component predominating in primary forms and a peripheral component predominating in secondary forms.

Neuroimaging findings, clinical characteristics and neuroendocrinological abnormalities in $\mathrm{CH}$ and in the other TACs pointed to a hypothalamic involvement, prompting the idea that this brain area could act cluster generator [20].

In animals, a direct connection between the posterior hypothalamus and the trigeminal nucleus caudalis through the trigemino-hypothalamic tract has been demonstrated [21]. Sensory information from trigeminally innervated territories is conveyed to the hypothalamus via the trigemino-hypothalamic tract [21]. On the contrary, stimulation of the posterior hypothalamus modulates the activity of trigeminal nucleus caudalis neurons: this effect is mediated by a number of substances, such as orexins [22]. In a $\mathrm{H}_{2}^{15} \mathrm{O}$ PET study conducted in patients with chronic $\mathrm{CH}$ under hypothalamic stimulation [13], hypothalamic stimulation induced activation in both the ipsilateral hypothalamic grey and the ipsilateral trigeminal system documenting for the first time a connection between the hypothalamus and the trigeminal system in humans. In this study, activation of the trigeminal nerve and ganglion did not produce any headache nor head sensation suggesting that trigeminal activation is not sufficient to fully explain $\mathrm{CH}$ pain [13]. Taking together data from animals and humans, there is now sufficient body of evidence indicating that the posterior hypothalamus plays a role in head pain modulation.

High-frequency hypothalamic stimulation to treat chronic drug-resistant $\mathrm{CH}$ was introduced in 2000 to inhibit hyperactivity of this brain area previously detected by PET [23].

So far, experience from more than 60 patients with drugresistant chronic $\mathrm{CH}$ treated with hypothalamic stimulation shows a remarkable improvement in about $60 \%$ of cases [24]. Hypothalamic stimulation is also effective in SUNCT [25-27] and in $\mathrm{PH}$ [28].

Acute stimulation does not improve ongoing $\mathrm{CH}$ attacks [29], and stimulation must continue for weeks or months before there is benefit [30].

Taken together, these observations suggest that the mechanism of action of hypothalamic stimulation is not the mere result of inhibition of hypothalamic neurons [30]. The increased threshold for cold pain in first trigeminal branch on the stimulated side in patients under chronic hypothalamic stimulation suggested modulation of the antinociceptive system [31].

Hypothalamic stimulation affects major pain-matrix areas: activation has been recorded in the thalamus, somatosensory cortex, precuneus, and anterior cingulate cortex, whereas deactivation occurs in the middle temporal gyrus, posterior cingulate cortex, and insula [13]. This suggests that it restores normal function of pain network in $\mathrm{CH}$ patients. The original hypothesis that the hypothalamus is the so-called $\mathrm{CH}$ generator was appealing, but recent neuroimaging findings and the accumulated experience with hypothalamic stimulation indicate other interpretations.

If the posterior hypothalamus was the $\mathrm{CH}$ generator, one would expect hypothalamic stimulation to trigger $\mathrm{CH}$ pain attacks, but this is not the case [30]. An alternative explanation about the role of the posterior hypothalamus in $\mathrm{CH}$ and TACs is that its activation leads to attack termination, thus regulating the duration of an attack [32]; this ability could explain the different attack durations in the various TAC forms.

Data accumulated in the last years, led to move beyond the search of a single trigger zone as previously thought in $\mathrm{CH}$. Brain areas involved in a $\mathrm{CH}$ attack [20] are almost the same of those traditionally regarded as the pain matrix; moreover, these areas show a huge overlap with brain areas modified by hypothalamic stimulation [13]. These areas play a major role also in autonomic, cognitive and affective functions. A derangement in one or more of these areas, or alternatively a deficit in their interactions, could be the cause of a permissive state leading to disinhibition of the 
hypothalamo-trigeminal pathway that in turn may start a pain attack.

Conflict of interest We certify that there is no actual or potential conflict of interest in relation to this article.

\section{References}

1. Ad Hoc Committee on Classification of Headache (1962) Classification of headache. JAMA 179(9):717-718

2. Headache Classification Committee of the International Headache Society (1988) Classification and diagnostic criteria for headache disorders, cranial neuralgias and facial pain. Cephalalgia 8 (Suppl 7)

3. Headache Classification Subcommittee of the International Headache Society (2004) The international classification of headache disorders: 2nd edn. Cephalalgia 24(Suppl 1):1-160

4. Goadsby PJ, Lipton RB (1997) A review of paroxysmal hemicranias, SUNCT syndrome and other shortlasting headaches with autonomic feature, including new cases. Brain 120:193-209

5. Nilsson Remahl I, Waldenlind E, Bratt J, Ekbom K (2000) Cluster headache is not associated with signs of a systemic inflammation. Headache 40:276-281

6. May A, Buchel C, Turner R, Goadsby PJ (2001) Magnetic resonance angiography in facial and other pain: neurovascular mechanisms of trigeminal sensation. J Cereb Blood Flow Metab 221:1171-1176

7. Matharu MS, Goadsby PJ (2002) Persistence of attacks of cluster headache after trigeminal nerve root section. Brain 125:976-984

8. Moskowitz MA (1990) Basic mechanisms in vascular headache. Neurol Clin 8:801-815

9. Goadsby PJ, Edvinsson L (1994) Human in vivo evidence for trigeminovascular activation in cluster headache. Neuropeptide changes and effects of acute attacks therapies. Brain 117:427-434

10. Favier I, van Vliet JA, Roon KI et al (2007) Trigeminal autonomic cephalgias due to structural lesions: a review of 31 cases. Arch Neurol 64:25-31

11. Kudrow L (1980) Cluster headache, mechanism and management, 1st edn. Oxford University Press, New York

12. Leone M, Attanasio A, Croci D et al (1997) The $m$-chlorophenylpiperazine test in cluster headache: a study on central serotoninergic activity. Cephalalgia 17:666-672

13. May A, Leone M, Boecker $\mathrm{H}$ et al (2006) Hypothalamic deep brain stimulation in positron emission tomography. J Neurosci 26:3589-3593

14. Jarrar RG, Black DF, Dodick DW, Davis DH (2003) Outcome of trigeminal nerve section in the treatment of chronic cluster headache. Neurology 60:1360-1362

15. Black DF, Dodick DW (2002) Two cases of medically and surgically intractable SUNCT: a reason for caution and an argument for a central mechanism. Cephalalgia 22:201-204

16. Torelli P, Cologno D, Cademartiri C, Manzoni GC (2001) Application of the International Headache Society classification criteria in 652 cluster headache patients. Cephalalgia 21:145-150
17. Cittadini E, Matharu MS, Goadsby PJ (2008) Paroxysmal hemicrania: a prospective clinical study of 31 cases. Brain 131:1142-1155

18. Cohen AS, Matharu MS, Goadsby PJ (2006) Short-lasting unilateral neuralgiform headache attacks with conjunctival injection and tearing (SUNCT) or cranial autonomic features (SUNA) - a prospective clinical study of SUNCT and SUNA. Brain 129:2746-2760

19. Leone M, Bussone G (1993) A review of hormonal findings in cluster headache. Evidence for hypothalamic involvement. Cephalalgia 13:309-317

20. May A, Bahra A, Buchel C, Frackowiak RS, Goadsby PJ (1998) Hypothalamic activation in cluster headache attacks. Lancet 352:275-278

21. Malick A, Strassman AM, Burstein R (2000) Trigeminohypothalamic and reticulohypothalamic tract neurons in the upper cervical spinal cord and caudal medulla of the rat. J Neurophysiol 84:2078-2112

22. Bartsch T, Levy MJ, Knight YE, Goadsby PJ (2004) Differential modulation of nociceptive dural input to [hypocretin] orexin A and $\mathrm{B}$ receptor activation in the posterior hypothalamic area. Pain 109:367-378

23. Leone M, Franzini A, Bussone G (2001) Stereotactic stimulation of posterior hypothalamic gray matter for intractable cluster headache. N Engl J Med 345:1428-1429

24. Magis D, Schoenen J (2012) Advances and challenges in neurostimulation for headaches. Lancet Neurol 11(8):708-719

25. Leone M, Franzini A, D’Andrea G, Broggi G, Casucci G, Bussone $\mathrm{G}$ (2005) Deep brain stimulation to relieve severe drugresistant SUNCT. Ann Neurol 57:924-927

26. Lyons MK, Dodick DW, Evidente VG (2008) Responsiveness of short-lasting unilateral neuralgiform headache with conjunctival injection and tearing to hypothalamic deep brain stimulation. J Neurosurg 26:1-3

27. Bartsch T, Falk D, Knudsen K, Reese R, Raethjen J, Mehdorn $\mathrm{HM}$ et al (2011) Deep brain stimulation of the posterior hypothalamic area in intractable short-lasting unilateral neuralgiform headache with conjunctival injection and tearing (SUNCT). Cephalalgia 31(13):1405-1408

28. Walcott BP, Bamber NI, Anderson DE (2009) Successful treatment of chronic paroxysmal hemicrania with posterior hypothalamic stimulation: technical case report. Neurosurgery 65:E997 (discussion E997)

29. Leone M, Franzini A, Broggi G, Mea E, Proietti Cecchini A, Bussone G (2006) Acute hypothalamic stimulation and ongoing cluster headache attacks. Neurology 67:1844-1845

30. Leone M, Franzini A, Proietti Cecchini A, Bussone G (2013) Success, failure and putative mechanisms in hypothalamic stimulation for drug-resistant chronic cluster headache. Pain 154(1):89-94

31. Jürgens T, Leone M, Proietti-Cecchini A, Busch V, Mea E, Bussone G, May G (2009) Hypothalamic deep-brain stimulation modulates thermal sensitivity and pain thresholds in cluster headache. Pain 146(1-2):84-90

32. May A (2005) Cluster headache: pathogenesis, diagnosis, and management. Lancet 366:843-855 